\title{
PESQUISA-INTERVENÇÃO FORMATIVA NA ESCOLA: DIALOGANDO COM GESTORES, PROFESSORES E ESTUDANTES
}

${ }^{1}$ Fabiane Salomão Souza, ${ }^{2}$ Irineu Aliprando Tuim Viotto Filho

${ }^{1}$ Mestre em Educação pelo Programa de Pós-graduação em Educação da Universidade Estadual Paulista - UNESP, Presidente Prudente, SP. Psicóloga da Secretaria Municipal de Educação, Presidente Prudente, SP. E-mail: salomaopsico@yahoo.com.br

${ }^{2}$ Doutor em Educação pela Pontifícia Universidade Católica de São Paulo - PUC. Professor do Programa de Pósgraduação em Educação e do Departamento de Educação Física da Universidade Estadual Paulista - UNESP, Presidente Prudente, SP.

\section{RESUMO}

Este trabalho apresenta as opiniões dos gestores de uma escola do Sistema Municipal de Educação de Presidente Prudente/SP sobre o processo de pesquisa-intervenção formativa realizado na escola. 0 objetivo da pesquisa foi criar um espaço coletivo de reflexão e discussão na escola, com intuito de propor novas formas de enfrentamento aos problemas que emergem no cotidiano escolar e ampliar a compreensão dos professores a respeito das determinações na produção das queixas escolares. 0 processo seguiu os fundamentos da Teoria histórico-cultural. Destacamos os resultados parciais obtidos por meio de entrevistas realizadas com os gestores da escola, no que se refere aos encontros de intervenção, os temas trabalhados e sobre as contribuições do processo. Os relatos demonstram que a intervenção possibilitou a construção de um espaço de reflexão e discussão coletivo de natureza crítica, favorecendo a quebra de concepções cristalizadas sobre as queixas escolares, rompendo com a patologização dos processos educacionais.

Palavras-chave: Educação. Pesquisa-Intervenção na escola. Psicologia. Teoria histórico-cultural. Psicologia Histórico-cultural.

\section{RESEARCH-TRAINING INTERVENTION IN SCHOOL: DIALOGANDO WITH MANAGERS, TEACHERS AND STUDENTS}

\section{ABSTRACT}

This work discuss the opinions of the school managers from the Municipal Education System of Presidente Prudente/SP about the research-intervention process held at the school. The objective of the research was to create a space for reflection and collective discussion in the school, in order to propose new ways of dealing with the problems which emerge in the daily school life and to broaden teachers' understanding about the determinations which feeds the school complaints production. The process followed the foundations of the historical-cultural theory. We highlight the partial results obtained through interviews with the school managers, regarding the intervention meetings, the themes studied and the contributions of the process. The reports describe that the intervention made possible the construction of a space for critical collective reflection and discussion favoring the breakdown of crystallized conceptions about school complaints, breaking the pathologization which comes from the educational processes.

Keywords: Education. Research-Intervention in the school. Psychology. Historical-cultural theory. Historical-cultural psychology.

\section{INTRODUÇÃO}

A Constituição brasileira define a educação como um direito de todos e dever do Estado, no entanto, os resultados obtidos em provas padronizadas, como Prova Brasil, ANA (Avaliação Nacional de Alfabetização) e IDEB (Índice de Desenvolvimento da Educação Básica), apontam para um processo de exclusão escolar 
caracterizado pelos baixos níveis de apropriação pelos estudantes dos conteúdos estudados, fato preocupante e que nos leva a pensar a efetividade de tais avaliações e, simultaneamente, $\mathrm{o}$ processo de ensino $\mathrm{e}$ aprendizagem na escola.

Meira (2014) ressalta que o sistema educacional de nosso país, desde o início da constituição das escolas brasileiras, tem engendrado condições para uma verdadeira exclusão dos sujeitos em relação aos conhecimentos. Souza (2001) também evidencia os problemas históricos relacionados à escolarização no Brasil e esclarece que desde a década de 1980, apesar do expressivo aumento na oferta de vagas nas escolas encontramos, contraditoriamente, altos índices de exclusão escolar, caracterizados pela evasão e repetência dos alunos, sobretudo daqueles oriundos das classes populares. Meira (2014, p. 07) ressalta

$$
\begin{aligned}
& \text { A "explicação" que vem } \\
& \text { sendo dada para esse } \\
& \text { fenômeno que se faz } \\
& \text { presente de modo maciço } \\
& \text { no cotidiano de nossas } \\
& \text { escolas e que revela } \\
& \text { inequivocamente em } \\
& \text { todas as estatísticas e } \\
& \text { avaliações educacionais } \\
& \text { disponíveis é bastante } \\
& \text { clara e direta: a escola é } \\
& \text { para todos, entretanto } \\
& \text { muitas crianças não } \\
& \text { aprendem as exigências da } \\
& \text { escola. A articulação mais } \\
& \text { consistente desse discurso } \\
& \text { falseador demanda a } \\
& \text { utilização de explicações } \\
& \text { advindas de variados } \\
& \text { campos da ciência, } \\
& \text { especialmente no que se } \\
& \text { refere as teorias sobre } \\
& \text { desenvolvimento humano } \\
& \text { e aprendizagem. }
\end{aligned}
$$

Meira (2014) faz um alerta a respeito da exclusão que os estudantes têm sofrido na atualidade e destaca a reflexão de Bourdieu, que denominou esse processo de "exclusão do interior". Esse processo de exclusão pode ser constatado nos resultados das avaliações externas, os quais têm comprovado que os estudantes, mesmo quando incluídos nas escolas, não se apropriam efetivamente do conhecimento, vivenciando, uma forma de inclusão excludente ou como afirma Sawaia
(2000) vivenciam uma situação de inclusão perversa em que os sujeitos sentem-se incluídos, no entanto, na verdade, continuam na situação de excluídos sociais (SAWAIA, 2000).

Para compreendermos estes fenômenos, devemos entender a escola não como uma instituição isolada da sociedade, mas como Leonardo, Leal e Franco $(2014$, p. 15) expõem:

[...] temos que a escola, como instituição social, não se constitui como realidade independente, mas como expressão de seu tempo histórico e da realidade da qual faz parte, sendo, portanto, determinada por condições históricas e sociais bem definidas. Ela exprime a sociedade capitalista a qual integra e, dessa forma, expressa, na atualidade, as ideias neoliberais dominantes, sendo o indivíduo o único responsável por seu sucesso ou fracasso.

Neste sentido, das contradições da sociedade capitalista movida pelos ideais neoliberais dominantes, que engendram a problemática acerca das queixas escolares e do processo de medicalização da educação devem ser analisados como resultantes dos processos de exclusão e de culpabilização nos quais o indivíduo é responsabilizado pelo seu fracasso.

A sociedade capitalista permeia todo o processo de exclusão escolar e social, as exigências quanto ao desempenho escolar e a ideia de superação e sucesso, alimentam a competição e excluem todos que não alcançam os padrões estabelecidos. Esses ideais adentram os muros da escola e impulsionam os mecanismos de exclusão, culpabilização e patologização, tão evidentes nas queixas escolares. Como destaca Silveira (1995) a respeito das afirmações de Coelho $(1989$, p.40) a relação entre educação e sociedade se estabelece de forma mecânica ou contigua, pois elas não são "duas realidades exteriores" e que "a relação concretamente existente entre elas é de determinação recíproca, ou seja, a sociedade sempre determina a educação e ao mesmo tempo é por esta determinada". 
Meira (2001) ressalta que a psicologia e outras áreas do conhecimento, utilizaram explicações biológicas para as dificuldades de aprendizagem dos alunos, desconsiderando fatores sociais e históricos determinantes nas relações escolares, atribuindo ao indivíduo a culpa pelo seu fracasso escolar, excluindo-o da apropriação qualitativa dos conteúdos escolares.

Essa exclusão verificamos nos resultados do IDEB, Martins e Marsiglia (2015) ressaltam que dos índices atingidos entre 2005 e 2013, nos anos iniciais do Ensino Fundamental, verifica-se um aumento nos resultados, partindo de 3.8 no ano de 2005 , chegando a 5.2 no ano de 2013. No entanto as autoras destacam que nos últimos anos do ensino fundamental ocorre uma queda nos resultados, quando comparados aos anos iniciais, sendo de 3.5 em 2005 e chegando a 4.1 no ano de 2013. No ensino médio as diferenças aumentam, demonstrando um declínio dos índices no decorrer do processo de escolarização, pois em 2005 os índices eram de 3.4, chegando a 3.7 em 2013.

Diante destes resultados, as autoras levantam os seguintes questionamentos: Como a escola pública tem desempenhado seu papel? Por que os índices caem durante o processo de escolarização? O que identificamos na realidade educacional de nosso país é que, mesmo a educação sendo um direito de todos, o fenômeno do fracasso escolar denunciado por Patto (1996) ainda se faz presente na escola pública brasileira, fato que evidencia a presença do fenômeno da exclusão educacional no seu interior.

Os estudos realizados por Patto (1996) analisaram as causas das dificuldades de aprendizagem de estudantes que não conseguiam se apropriar de forma satisfatória dos conteúdos escolares, ou que abandonavam a escola por serem vítimas dos processos de exclusão escolar e social. A mesma autora também realizou críticas a forma como os psicólogos escolares, baseados no modelo médico-organicista, desenvolveram práticas de exclusão na educação, isso por meio da psicometria, cujo objetivo restringia-se a diagnosticar e classificar os estudantes que não se encaixavam nos padrões estabelecidos pela sociedade. Segundo a autora, tais práticas não auxiliavam os estudantes, apenas serviam para rotulá-los e patologizá-los (PATTO, 2000). Neste sentido ressaltamos suas palavras a respeito da psicometria:
Discutir os testes não é pôr em confronto gostos e opiniões pessoais; muito menos transformar o debate em rinha ou ringue para divertir a platéia. 0 que está em pauta não são os testes em si mesmos, mas uma discussão teórica de caráter muito mais amplo: o da própria concepção de ciência, de homem e de sociedade que lastreia uma Psicologia que está na base da criação de instrumentos para fins de avaliação quantitativa e classificação de indivíduos e grupos, Psicologia esta que tem sido qualificada como positivista, instrumental, objetivista, fisicalista (PATTO, 2000, p. 74).

Estes problemas denunciados por Patto (1996) e, posteriormente, por outros autores, como Meira (2001), Souza (2010), Franco (2009), Meira e Facci (2007) não ficaram no passado, ainda estão presentes nas escolas brasileiras e alimentam práticas excludentes e preconceituosas. Segundo Asbahr (2012, p.94) "muitas crianças com dificuldades de aprendizagem são encaminhadas para um diagnóstico psicológico que possa justificar cientificamente a exclusão do aluno da e na escola", sendo que muitos diretores, coordenadores e professores anseiam por uma avaliação psicológica que revele a razão dos alunos não aprenderem e, quando encaminhados, geralmente tais avaliações, baseadas em testes de inteligência e personalidade, indicam a presença de deficiências e distúrbios mentais nas crianças, testes estes na maioria inadequados e que transmutam as desigualdades sociais em dificuldades individuais, legitimando cientificamente, o rótulo de "crianças problema" na escola.

Collares e Moysés (1994) afirmam que a incorporação das concepções organicistas no campo educacional, eleva o número de encaminhamentos de estudantes com queixas de problemas de aprendizagem aos especialistas considerados da saúde, tais como neurologistas, 
psiquiatras, psicólogos e terapeutas, fato que contribui para o aumento dos diagnósticos relacionados a distúrbios mentais junto às crianças na escola. $O$ aumento dos diagnósticos resulta no processo de medicalização da educação, no qual questões de natureza escolar e social são naturalizadas e reduzidas a explicações biológicas. Assim, o que vemos em nosso trabalho na educação é o aumento abusivo no uso de medicação para os alunos, desde a educação infantil.

Diante dessa realidade, Meira (2014) destaca que os pressupostos teóricos da teoria histórico-cultural e da pedagogia histórico-crítica, possibilitam a compreensão ampliada destes fenômenos e ressaltam a importância do papel da educação escolar no desenvolvimento de cada indivíduo singular. Nas palavras da autora

À luz desses pressupostos,
coloca-se claramente o
foco fundamental da
atuação do psicólogo
escolar: contribuir para a
constituição de processos
educativos
qualitativamente
superiores
possibilitem que as novas
gerações se apropriem dos
conhecimentos
historicamenter pela
acumulados
humanidade, construindo
e ampliando a sua
capacidade de
pensamento crítico.

Estes problemas destacados fazem parte da realidade do trabalho de psicologia realizado no Centro de Avaliação e Acompanhamento (CAA), serviço formado por uma equipe interdisciplinar, situado na Secretaria Municipal de Educação de Presidente Prudente/SP. Este serviço recebe anualmente encaminhamentos de alunos com queixas de problemas de aprendizagem e de comportamento na escola.

Os motivos que estimularam a realização de uma pesquisa-intervenção formativa no contexto escolar decorrem do aumento significativo de encaminhamentos de estudantes para avaliação e, sobretudo, da nossa participação no GEIPEE-thc (Grupo de estudos, intervenção e pesquisa em educação escolar e teoria histórico-cultural), além de reflexões oriundas dos estudos de Patto (1996), Machado e Souza (2001), Tanamachi, Proença e Rocha (2000), Viotto Filho (2005) e Referências Técnicas do Conselho Federal de Psicologia (2013), entre outros, a respeito dos princípios teóricos críticos que norteiam a atuação do psicólogo no contexto escolar.

A pesquisa-intervenção formativa foi realizada em uma escola do sistema municipal de ensino de Presidente Prudente/SP, no intuito de romper com o modelo de atuação clínico e desenvolver uma prática psicopedagógica crítica na escola, no sentido de compreender as multideterminações do fracasso escolar. Como afirma Meira (2014), reconhecendo esse fenômeno não como uma dificuldade do aluno, mas sim como um processo complexo, resultante de condições sociais e históricas e produzido no cotidiano das instituições escolares.

Esta pesquisa teve como objeto de estudo o processo de intervenção no contexto escolar e seus desdobramentos na prática pedagógica dos professores. Os sujeitos da pesquisa foram os professores, gestores e os estudantes de uma sala de aula do 3 ㅇ ano do Ensino fundamental, ciclo I da escola. A instituição escolar localiza-se em bairro periférico da cidade, com número elevado de queixas de problemas de aprendizagem e baixo desempenho no IDEB (Índice de desenvolvimento educação básica).

O processo de pesquisa-intervenção formativa seguiu os pressupostos da Teoria histórico-cultural e Pedagogia histórico-crítica, enfatizando a função específica da escola como transmissora dos conhecimentos sistematizados e a importância das relações sociais e apropriações culturais para o desenvolvimento do psiquismo dos alunos. Esclarecemos que o conceito de pesquisa-intervenção formativa tem sido construído ao longo dos anos de trabalho no interior do GEIPEE-thc, que definimos como um trabalho coletivo, de natureza interventiva, pois atuamos ao lado dos sujeitos com quem trabalhamos, com a finalidade de proporcionar aos sujeitos participantes (gestores, professores, estudantes e familiares) o devido acesso a teorias críticas da educação e da psicologia, além de discussão coletiva sobre a realidade da escola, seus problemas e dificuldades, na busca coletiva de caminhos para a superação das dificuldades encontradas e criação de condições educativas voltadas à construção da consciência crítica dos sujeitos, acreditando que, para além de uma pesquisa-ação (THIOLLENT,2000), a pesquisa 
intervenção formativa possibilita o desenvolvimento dos sujeitos para enfrentarem tanto os problemas localizados, como também os forma criticamente, via processo de construção de consciência crítica, para lidar com a realidade e transformá-la, conforme suas necessidades, segundo orientação de Davidov (1988), Vazquez (1988) e Saviani (2001).

Esclarecemos que adotamos o termo intervenção em decorrência da proposição de atividades in loco na escola, em que os sujeitos (gestores, professores, estudantes e familiares) têm participação ativa ao lado dos pesquisadores na resolução das dificuldades e encaminhamento dos resultados da pesquisa. O conceito formativo, por sua vez, decorre dos trabalhos didáticoformativos realizados por Davidov (1988) na União Soviética na década de 1980, conforme mencionamos acima, quando o autor afirma o processo de pesquisa como necessário para investigar a formação e o desenvolvimento dos aspectos conscientes da relação dos seres humanos com o mundo. Neste sentido, o termo pesquisa-intervenção formativa, segundo nossa definição, indica a natureza do trabalho coletivo e educativo desenvolvido pelos membros do GEIPEE-thc (Grupo de Estudos, Intervenção e Pesquisa em Educação Escolar e teoria históricocultural) na escola que enfatiza o método materialista histórico dialético e suas categorias de análise no processo de compreensão da realidade escolar e no desenvolvimento dos seres humanos na relação com os conhecimentos historicamente acumulados pela humanidade (SAVIANI, 2000).

Após a conceituação da metodologia de pesquisa aplicada no trabalho, informamos que neste artigo apresentaremos a opinião dos gestores a respeito do processo de pesquisaintervenção realizado na escola; dados esses obtidos por meio de entrevista, um dos procedimentos adotados para a coleta de dados durante o processo de pesquisa-intervenção formativa realizado na escola.

\section{PROCECIMENTOS METODOLÓGICOS DA PESQUISA}

O processo de pesquisa-intervenção formativa na escola junto aos professores e gestores ocorreu quinzenalmente, em encontros durante as HTPCs, por meio de discussão de temas em grupo e compartilhamento de experiências profissionais. A pesquisa foi autorizada pelo comitê de ética em pesquisa, com número de protocolo 109/2009.
Os encontros foram realizados durante 0 ano de 2016 e contaram com a participação de professores, diretora e orientadora pedagógica da escola. Foram desenvolvidos estudos e discussões a respeito do fracasso escolar, problemas de aprendizagem, estratégias de ensino e aprendizagem, entre outros, sempre acompanhadas de reflexões e discussões coletivas. Os temas, desenvolvidos durante os encontros, partiram do levantamento realizado com o grupo no primeiro encontro e das necessidades que emergiram no decorrer do processo. A proposta feita ao grupo foi de realizar um trabalho construído de forma coletiva na escola.

Para a coleta de dados do processo de pesquisa utilizamos a observação sistemática das atividades realizadas, entrevistas e questionários, assim como um texto escrito pelos professores para avaliar as situações vividas durante a pesquisa-intervenção formativa. As discussões de temas escolhidos pelos professores foram conduzidas pelos autores desse trabalho e membros do GEIPEE-thc, assim como pelos especialistas da equipe do Centro de Avaliação e Acompanhamento (CAA), da Secretaria Municipal de Educação de Presidente Prudente/SP. O processo de pesquisa-intervenção foi desenvolvido de fevereiro até novembro de 2016.

Adotamos o termo intervenção baseado em Damiani (2012), Sannino (2011), Machado (1997), Viotto Filho (2005), dentre outros, os quais utilizam este termo para definir os seus trabalhos e pesquisas voltados à escola e salientamos que o termo intervenção tem sido historicamente utilizado na proposição de atividades in loco, na qual os sujeitos têm participação ativa ao lado dos pesquisadores. Neste sentido, o termo pesquisa-intervenção formativa define a natureza do trabalho desenvolvido na escola, no qual os pesquisadores (autores deste trabalho), membros do GEIPEE-thc e membros do CAA, desenvolveram junto aos sujeitos da escola, enfatizando um processo coletivo de trabalho.

Entendemos por processo de pesquisaintervenção formativa a ação intencional e planejada de um coletivo de profissionais da educação, devidamente respaldados pelo método materialista histórico dialético e por teorias críticas da educação e da psicologia, com a finalidade de investigar a realidade escolar por dentro da escola, a fim de transformar as relações sociais e o trabalho educativo nela 
realizado e possibilitar a transformação da consciência dos sujeitos que dela participam, principalmente os professores e gestores, como também os estudantes, numa direção crítica e emancipatória.

\section{RESULTADOS E DISCUSSÃO}

A partir da realização da entrevista com a diretora e orientadora pedagógica da escola foram obtidos dados a respeito do processo de intervenção formativa realizado na escola e apresentaremos alguns resultados parciais, destacando as categorias "encontros de intervenção", "avaliação do processo de pesquisa-intervenção", "temas trabalhados" e "contribuições do processo de pesquisaintervenção", "pontos positivos" e "resultados atingidos".

Em relação à opinião da diretora sobre os "encontros de intervenção" realizados com os professores, a mesma os avaliou de forma positiva, pois verificou as mudanças nas ações e concepções do grupo. Destacou que no início dos encontros os professores se sentiam culpados pelas dificuldades das crianças, culpados pelo fracasso escolar, nas palavras da diretora "todo fracasso escolar acaba sendo, é, o professor o culpado".

A diretora identificou o ciclo da culpabilização, no qual especialistas e familiares culpam os professores, estes culpam as famílias e os estudantes, que culpam a escola, e assim, os problemas persistem sem modificação e os sujeitos ao se culparem, não refletem a respeito das múltiplas determinações envolvidas na produção destes problemas. A diretora avalia que o processo de intervenção possibilitou a quebra destas concepções a respeito do fracasso escolar, abrindo espaço para novas formas de pensar a produção destes fenômenos, em suas palavras, a intervenção proporcionou "quebrar um pouco esse mito de que a dificuldade na aprendizagem é só por conta do professor".

[...] professores estavam bastante apreensivos porque os professores, eles acabam tendo a consciência de que todo fracasso escolar acaba sendo, é, o professor o culpado. Eles sem exceção, eles pensaram assim, nossa! Mais um grupo pra vir aqui e falar que $o$ aluno tem dificuldade porque nós não trabalhamos direito, nós não trabalhamos a consciência. Então, os professores acabam pegando essa culpa, porque as famílias falam muito isso, então muitos professores acabam jogando pra família, essa culpa do fracasso, a culpada dificuldade do aluno e as famílias acabam retribuindo esse fracasso pra escola e para os professores, diretamente para os professores e essa intervenção foi muito boa porque na verdade deu para tirar, quebrar um pouco esse mito de que a dificuldade na aprendizagem é só por conta do professor[...](Diretora, Informação verbal, 2017, grifos nossos).

Eu achei interessante, por que a escola foi lembrada no processo de intervenção, achei importante nesse sentido, que é uma escola de periferia, com alguns problemas e lembraram-se da escola, pensaram na escola para esse processo de intervenção (Orientadora pedagógica, Informação verbal, 2017).

Podemos observar nas palavras da gestora que um processo de intervenção no interior da escola, junto aos sujeitos, contribuindo para o encaminhamento de reflexões acerca das dificuldades que emergem no cotidiano escolar, possibilita a reflexão crítica sobre a prática. Neste sentido, como afirma Viotto Filho (2005, p.19), a psicologia, a pedagogia e demais áreas que atuam na escola numa perspectiva crítica, podem "contribuir para uma compreensão concreta dos sujeitos escolares, assim como das relações sociais presentes na escola na direção da transformação qualitativa das práticas pedagógicas em direção à práxis transformadora". 
Torna-se importante a definição de Vazquez (1988) sobre práxis, pois, como toda atividade humana, a práxis requer criação intencional humana, ou seja, é uma atividade voltada a objetivos, finalidades, cujo seu cumprimento requer atividade cognoscitiva dos sujeitos da práxis, no entanto, esclarece o autor, o que caracteriza a atividade prática como práxis é o caráter real, objetivo, da matéria-prima sobre a qual se atua, os meios e instrumentos com que se exerce a ação e seu resultado ou produto (VAZQUEZ, 1988).

$\mathrm{Na}$ escola, podemos pensar que a educação escolar configura-se como uma forma específica de práxis, em que se procura a unidade entre teoria e prática e não uma prática pura propriamente dita, conforme esclarece Ribeiro (2001). Nas palavras da autora:

A atividade educacional
está determinada
imediatamente pela
finalidade de satisfação da
necessidade que todo o
ser humano tem de
compreender a um tempo,
o que foi feito/produzido,
o que está sendo
feito/produzido e o que
pode, tem que ser
feito/produzido. Neste
processo se insere e
adquire sentido o que
cada um fez/produziu,
está fazendo/produzindo e
pode, tem
responsabilidade de
fazer/produzir (RIBEIRO,
2001).

E continua a autora afirmando que "a finalidade imediata da educação (muitas vezes não cumprida) é a de tornar possível um maior grau de consciência, ou seja, de conhecimento, compreensão da realidade da qual nós, seres humanos, somos parte e na qual atuamos teórica e praticamente". Podemos dizer, segundo a autora, que a educação opera transformações de natureza subjetiva, transforma as consciências dos sujeitos, "ainda que exigida pela necessidade humana de operar praticamente sobre a realidade objetiva e de transformá-la objetivamente, concretamente, materialmente" (RIBEIRO, 2001, p.29-30).

Salientamos que processo de pesquisaintervenção formativa realizado na escola depara-se, constantemente, com os processos de alienação social que adentram a escola e à vida dos professores. Esse fenômeno social, portanto, deve ser objeto de intensa reflexão crítica na escola, sobretudo porque adentra a vida das pessoas sem pedir permissão e de forma sútil, transformando consciências, no entanto, causa prejuízos enormes no processo educativo em geral e na prática pedagógica do professor, assim como na relação social entre os alunos na escola, pois os sujeitos alienados, separados da consciência crítica, acabam por reproduzir a alienação sem sequer percebê-la, sem a devida crítica, fato nefasto para as relações sociais na escola e, especificamente, para o trabalho educativo do professor.

Oliveira (1996) afirma que a alienação corresponde a separação entre a essência e a existência humana, ou ainda, como afirma Leontiev (1978), o resultado da fragmentação entre sentido e significado das relações sociais, situações em que o indivíduo distancia-se de uma compreensão coerente da realidade e sua totalidade. Nunes e Viotto Filho (2016) ressaltam a definição de Rossler (2004, p. 110) sobre o processo de alienação:

[...] quando a estrutura da vida cotidiana se hipertrofia, tornando-se a única forma de vida do indivíduo; quando sua vida se resume num conjunto de atividades voltadas essencialmente para a sua reprodução, para a reprodução de sua particularidade, apresentando, assim, modos rígidos de pensar, sentir e agir, isto é, determinando um modo de funcionamento psíquico (intelectual e afetivo) cristalizado, que não pode ser rompido mesmo nas situações que o exigem; nesses casos, estamos diante de um fenômeno de alienação. Trata-se, portanto, de uma estrutura social alienada, de um cotidiano alienado e, consequentemente, de um psiquismo cotidiano alienado. 
Neste sentido, avaliamos que os professores da escola ao repetirem os problemas cotidianos, sem refletir acerca da produção social dos mesmos, encontravam-se alienados, fragmentados na sua forma de pensar a realidade. Oliveira (1996) aponta que desvendar a realidade, conhecer suas múltiplas determinações e iniciar uma prática crítica, constitui o primeiro passo para a transformação da realidade. Podemos compreender, portanto, que as reflexões realizadas durante os encontros de intervenção proporcionaram o primeiro passo no processo dinâmico e contínuo de conhecimento da realidade escolar, retirando dos professores o peso da culpa acerca das causas do fracasso escolar.

A diretora e a orientadora pedagógica avaliaram de forma positiva o processo de intervenção realizado com os professores e enfatizaram que o mesmo ocorreu em etapas e possibilitou a construção paulatina do grupo, que iniciou com muita resistência e no decorrer dos encontros, convenceu os professores de que o trabalho que estava sendo realizado tinha como objetivo a melhora do trabalho pedagógico e das relações sociais na escola. A orientadora avalia que "dali saíram alguns frutos, pensamentos, críticas, pessoas discutindo sobre a própria prática".

Foi como um parto, no início ele foi construído com muita dor porque houve bastante resistência, houve bastante resistência dos professores... então, a principio, foi como um parto mesmo, muita dificuldade na aceitação dos professores; os professores se sentiam vigiados com o grupo dentro da escola, então, a princípio, foi bastante difícil até a gente se convencer com o trabalho e que o objetivo era realmente auxiliar tanto os professores quanto os alunos. Então, esse projeto foi avaliado como superprodutivo, mas, a princípio, teve bastante dor sim, nós tivemos bastante dificuldade no princípio (Diretora,
Informação verbal, 2017, grifos nossos).

Eu avalio de forma positiva, porque dali saíram alguns frutos, pensamentos, críticas, pessoas discutindo sobre a própria prática e pessoas querendo estudar mais, se aprofundar mais no tema para poder melhorar sua pratica e transformar em melhoria para a criança, em pratica na sala de aula para a criança (Orientadora pedagógica, Informação verbal, 2017, grifos nossos).

Souza (2010) salienta que a psicologia deve realizar estudos na escola para compreender seu cotidiano, analisar os processos e as relações que nela se formam e atuar junto aos sujeitos que constituem o grupo escolar, estabelecendo com eles vínculos de confiança. Neste sentido, verificamos, pelas palavras da diretora da escola, que os professores aderiram ao processo de intervenção a partir do momento em que se convenceram de que o trabalho dos pesquisadores e os demais participantes da pesquisa-intervenção formativa, não estavam na escola para culpabilizá-los ou mesmo vigiá-los, mas, para refletir junto e pensar possibilidades de transformação humana e social.

Os temas abordados durante os encontros com os professores foram considerados pertinentes pelas gestoras da escola, verificamos que a orientadora pedagógica ressalta que os temas foram escolhidos pelo próprio grupo de professores e, desta forma, atenderam o interesse dos próprios professores. Estudar temas escolhidos por eles foi positivo, pois reforçou a proposta de um trabalho formativo, ou seja, construído na escola e ao lado dos sujeitos que constituem a escola e voltado para o seu processo de desenvolvimento. Como destaca a diretora, todos os temas abordados tiveram sua contribuição, no entanto, o fracasso escolar foi um tema que possibilitou reflexões essenciais em relação às dificuldades de aprendizagem dos alunos, não culpabilizando o professor ou o aluno, mas voltando-se, como comenta a diretora da escola "para o conjunto 
[da escola] que não estava adequado, para que todos pudessem se desenvolver".

A cada tema abordado, por exemplo, quando foi apresentado o tema do fracasso escolar, eu vi que eles [professores] estavam bem armados, porque eles esperavam que o fracasso escolar naquele momento fosse atribuído à escola e aos professores, e não, e a gente acabou discutindo $o$ conjunto de atitudes; no conjunto não estava adequado, para que todos alunos pudessem se desenvolver na questão da aprendizagem e aí isso foi bacana, porque foi feito esse trabalho, um trabalho bem produtivo e a gente percebeu que com o tempo do projeto os professores acabaram entrando no projeto mesmo e eles acabaram se soltando, com perguntas e muitas vezes tendo um bate papo onde os professores participavam, criticavam, sugeriam, e isso foi muito bacana (Diretora, Informação verbal, 2017, grifos nossos).

Eu achei que foram temas pertinentes, temas importantes, temas que a gente precisava refletir; todos os temas eu gostei, até porque foram temas escolhidos pela própria equipe, então foi produtivo, por conta disso (Orientadora pedagógica, Informação verbal, 2017, grifos nossos).

Discutir temas relevantes e pertinentes ao espaço escolar é uma das atribuições do psicólogo escolar e demais profissionais que atuam na escola, assumindo "o compromisso de contribuir, com seus conhecimentos e práticas, para a compreensão das questões que envolvem a política educacional e suas implicações no trabalho docente" (CONSELHO FEDERAL DE
PSICOLOGIA, 2013, p. 57). Segundo as referências para atuação dos psicólogos na educação básica (2013), os profissionais engajados em uma atuação crítica, podem trabalhar temas sobre o processo de aprendizagem e desenvolvimento e aspectos envolvidos nas relações interpessoais que permeiam os processos educacionais, contribuindo com reflexões teórico-práticas voltadas a humanização.

As gestoras da escola apontam como "contribuições do processo de pesquisaintervenção", que os professores perceberem a importância de refletirem a respeito dos motivos que produzem as dificuldades dos estudantes, desde o primeiro ano; a diretora destaca que "foi um momento que os professores puderam refletir porque que os alunos tinham dificuldade", com isso, passaram a avaliar a efetivação do trabalho pedagógico desenvolvido com os alunos. Esta atitude revela uma mudança relevante em direção à ruptura da culpabilização e patologização das queixas escolares, pois quando os professores repensam o processo de ensino e aprendizagem, incluindo-se neste processo, deixam de reproduzir preconceitos e cristalizações sobre as causas das dificuldades de aprendizagem. Com isto, passam a refletir sobre a produção da queixa escolar e sobre a história dos estudantes no espaço escolar. Sobre esta questão Souza (2010, p. 144) afirma que o reconhecimento da história dos alunos "introduz um procedimento com possibilidade de reflexão sobre a criança, os mecanismos escolares e as práticas pedagógicas, de modo a se problematizar a vida institucional, questionar o estabelecido e criar rupturas com as práticas cristalizadas".

A diretora ainda destacou que os professores começaram a valorizar os estudantes na realização de outras atividades na escola tais como,

[...] nós percebemos os alunos muito mais soltos, muito mais participativos, muito mais motivados; percebemos que alguns professores começaram a pensar, olha, essa questão não dá certo porque que os alunos vem com dificuldade desde 0 primeiro ano, nós precisamos pensar; então, foi um momento que os professores puderam 
refletir porque os alunos tinham dificuldades e porque, esses [mesmos] alunos se saíam muito bem no desenho, se saíam muito bem na hora da educação física, então, deu para os professores se questionarem mesmo 0 que é que tem de errado com nosso trabalho (Diretora, Informação verbal, 2017, grifos nossos).

[...] no meu trabalho foi pensar na minha parte como orientadora da escola, para estar refletindo como a gente trabalha essa questão, as crianças com dificuldade, e a gente pensar também num trabalho diferenciado para elas (Orientadora pedagógica, Informação verbal, 2017).

Souza (2010) afirma que deve-se partir da demanda dos professores, no caso aqui exposto, os professores da escola começaram questionar "o que é que tem de errado com nosso trabalho" e segundo a autora, não se limitar a ela, mas ampliar o campo das reflexões e discussões, até chegar aos aspectos que envolvem 0 funcionamento da escola. Estes momentos de reflexão coletiva são importantes, segundo a autora, pois proporcionam reflexões sobre a prática docente, "assim como os fatores implicados na produção do fracasso escolar" (SOUZA, 2010, p. 145).

As gestoras da escola destacam que os "pontos positivos" foram a auto avaliação dos professores, que repensaram sua prática pedagógica, e o trabalho coletivo, pois durante os encontros houve a interação entre os professores, compreendendo que as dificuldades enfrentadas com os estudantes não eram de responsabilidade apenas do professor da sala daquele ano, mas sim da escola toda. Meira (2001) destaca que o psicólogo escolar pode mediar o processo no qual os professores realizam reflexões sobre as determinações da queixa escolar. Neste sentido, os encontros com os professores e gestores mediados pelos responsáveis pelo processo de intervenção contribuíram no encaminhamento destas reflexões.

[...] foi a auto avaliação desses professores eles puderam auto avaliar o trabalho deles como é que era esse trabalho que precisava ser mudado nesse trabalho[...] (Diretora, informação verbal, 2017).

[...] foi a interação com o grupo, porque o aluno que está no primeiro ano pode não ser desse professor mas no ano que vem ele vai ser então houve uma interação com objetivo de caminhar todos juntos pra que esses alunos não tivessem dificuldade e um professor precisava se juntar ao outro mesmo pra ver a dificuldade que não era dele naquele momento mas que no ano seguinte poderia ser[...] (Diretora, informação verbal, 2017).

A diretora e a orientadora também destacam como pontos positivos a estrutura proporcionada nas HTPCs, pois eram encontros previamente organizados, com exposição de temas relevantes aos sujeitos da escola. Verificamos que a orientadora pedagógica enfatiza o sentimento de valorização da escola por ela ter sido escolhida para o desenvolvimento da pesquisa.

[...] as HTPCS elas eram bem mais estruturadas isso dava um suporte muito legal e uma segurança as HTPCs elas eram estruturadas com começo, meio e fim e temas que eram pertinentes à escola [...] (Diretora, informação verbal, 2017).

[...] foi pensar numa formação em HTPC, [...] foi trazer temas que saíram da escolha dos próprios professores e outro ponto positivo que eu achei foi 
pensar na escola mesmo, uma escola que é tão marginalizada, tão esquecida, pensar na escola em si (Orientadora pedagógica, informação verbal, 2017).

Quanto aos "resultados atingidos", a diretora e orientadora pedagógica apontam a elevação da autoestima dos estudantes e a conquista da alfabetização como resultados do processo de intervenção na escola. Avaliam que os estudantes se apresentaram mais satisfeitos, motivados e sentindo-se inseridos no processo de ensino e aprendizagem. A orientadora afirma que "a gente achava que não iam aprender, que não iriam ser alfabetizadas, que estão avançando" nesta fala verificamos o quanto a escola havia atribuído aos estudantes um estereótipo, um estigma, por serem os estudantes da sala de aula com problemas de aprendizagem. Em relação à autoestima Franco e Davis (2014, p. 57) afirmam:

[...] crianças e jovens que vivenciam situações de não aprendizagem no contexto escolar precisam de condições de vida que permitem 0 pleno desenvolvimento humano, para que significados e sentidos não sejam tomados de forma fragmentada. Falar em autoestima sem considerar as múltiplas relações em que o indivíduo se constitui não possibilita uma análise mais aprofundada da realidade, tampouco do psiquismo.

Franco e Davis (2014) afirmam que a autoestima não pode ser transformada sem a vivência nas relações sociais. As autoras complementam que:

[...] a escola é um lokus fundamental de humanização. Nesse sentido, precisamos lutar por uma escola que ensine bem a todos! Sabemos, agora melhor do que nunca, que a autoestima não pode ser produzida, fabricada ou mudada, como apregoam certas pedagogias idealistas. Ela depende das condições de vida dos sujeitos e, nesse sentido, de uma escola de qualidade.

Destacamos as palavras das gestoras:

Os resultados foram atingidos sim, é a questão dos alunos serem alfabetizados

autoestima destes alunos os primeiros alunos que a gente conseguiu tirar desta sala com dificuldades e colocar em outra sala, uma sala mais avançada é a alegria que os alunos tinham ou alegria e satisfação que eles tinham em aprender ler e escrever cada vez que eles me procuravam e falavam assim, diretora eu já sei ler e escrever a gente via a satisfação no olhar nessas crianças e isso é muito gratificante isso não tinha preço quando eles me procuravam e falavam você já sabia que eu sei ler então as crianças estavam sim bem inseridas e muito motivadas a gente percebia isso no dia a dia (Diretora, informação verbal, 2017, grifos nossos).

$\mathrm{Na}$ escola o que eu vejo de mais importante foi as crianças da escola, que fizeram parte desse projeto tiverem a autoestima um pouco mais elevada, crianças que estavam bem inseguras, elas avançaram na sua aprendizagem, tiveram uma chance a mais de aprender, para mim o resultado, é que ficou bem claro foram as crianças que a gente achava que não iam aprender, que não iriam ser alfabetizadas, que estão 
avançando (Orientadora pedagógica, informação verbal, 2017, grifos nossos).

Enfim, o trabalho realizado com os sujeitos da escola e na própria escola proporcionou condições diversificadas a todos os sujeitos participantes de reverem concepções e ações, assim como realizarem crítica ao sistema e ao processo educacional realizado na escola e, desta forma, rever de forma consciente a sua prática pedagógica como uma forma de luta, uma forma de luta em defesa da escola pública, como luta por mais e melhores condições de trabalho, por uma organização escolar que se responsabilize pelos sujeitos da escola, enfim, uma luta pela escola, pela formação e pelo ensino de qualidade para todos, pois os benefícios são muitos, conforme foi possível constatar aos analisarmos os dados coletados em nossa pesquisa-intervenção formativa.

\section{CONCLUSÕES}

O processo de pesquisa-intervenção formativa proposto, envolvendo a participação coletiva dos sujeitos que constituem a escola, gestores, professores e estudantes, objetivou a criação de um espaço de ação, reflexão e ação na escola. Constatamos a partir da análise dos dados obtidos nas entrevistas com as gestoras, que as ações realizadas possibilitaram um primeiro passo em direção a este objetivo.

A proposta de um projeto de pesquisaintervenção na escola objetivou o rompimento com o modelo clínico-psicológico de atuação, baseado em visões biologizantes e naturalizantes do psiquismo humano, que não favorecem o desenvolvimento dos sujeitos e apenas os culpabiliza, assim como psicopatologiza os fenômenos educacionais.

Verificamos que o grupo de professores conseguiu quebrar algumas concepções acerca dos problemas de aprendizagem dos alunos, refletindo sobre os mecanismos de culpabilização presentes na escola. Os professores passaram olhar as particularidades dos alunos e a refletir sobre as práticas pedagógicas desenvolvidas com os mesmos.

Diante dos resultados obtidos ao encerramento do processo de pesquisaintervenção, consideramos a importância da realização de projetos de intervenção formativa no interior da escola, principalmente junto aos sujeitos que a constituem. Porém ressaltamos que se faz necessário uma atuação que entenda o homem em seu movimento histórico-social, rompendo com visões naturalizantes e fragmentadas sobre o ser humano, assim como sobre a escola, a educação e a sociedade.

Por fim, queremos salientar que a escola precisa viver transformações necessárias, ou poderíamos dizer, a escola precisa melhorar o seu processo de humanização, isso é condição fundamental para a construção de sujeitos conscientes, verdadeiros cidadãos, como normalmente se defendem nos planos pedagógicos da escola. No entanto, esse processo não acontece espontaneamente, há que se trabalhar na escola, e a pesquisa-intervenção formativa coloca pesquisadores, equipe interdisciplinar e grupo de pesquisa trabalhando ao lado dos sujeitos participantes da escola e essa é uma atividade que consideramos práxis, resgatando o termo Vazqueano e o psicólogo, certamente, ao lado dos outros profissionais da educação, faz parte desse grupo e tem papel importante no processo de construção da consciência crítica na escola.

Queremos lembrar, mais uma vez, que a atividade educacional escolar é uma forma específica de práxis e deve ser compreendida nessa complexidade, fato que levará a ações práticas efetivas na escola, ações prático-teóricas conscientes que não se reduzem a realizar tarefas imediatas, como o famoso "apagar fogo" tão presente nas escolas pública. A ação práticoteórica na escola configura-se como práxis porque cria as condições para o enfrentamento de problemas imediatos sem tornar-se uma ação pragmática, pelo contrário, é conquistada a partir de muito estudo e reflexão teórica coletiva, como procuramos realizar em nosso projeto de intervenção e pesquisa formativa, pois somente nessa direção torna-se possível lidar com os problemas e dificuldades e, ao mesmo tempo, possibilitar aos sujeitos da intervenção a construção de consciências criticas, pois são os sujeitos participantes da escola os responsáveis pela efetivação de transformações qualitativas no seu interior.

Finalizamos nossas reflexões lembrando Ribeiro (2001, p.44) quando salienta:

A atividade educacional escolar, sendo uma forma específica de práxis, produz o resultado pretendido desde que, 
entre outras coisas importantes, não nos distanciemos e muito menos ignoremos a finalidade mediata a que toda forma específica de atividade humana está subordinada, ou seja, a finalidade de construção, produção, constituição de um ser humano cada vez mais humano.

Com as discussões possibilitadas no processo de pesquisa-intervenção formativa realizada, o grupo de professores e as gestoras, passaram a refletir criticamente sobre as queixas escolares, deixando de se culpar, ou mesmo culpar a crianças, por estes problemas. Enfim, diante dos resultados obtidos, constatamos que um trabalho de pesquisa dessa natureza se faz necessário na escola, o qual, realizado coletivamente, pode proporcionar transformações qualitativas nos sujeitos que dela participam e engendrar mudanças de concepções acerca dos problemas que se apresentam no cotidiano escolar e na prática pedagógica engendrada pela transformação das consciências dos sujeitos na escola.

\section{REFERÊNCIAS}

ASBAHR, F. S.F. Novas velhas explicações sobre o fracasso escolar. In: VIOTTO FILHO; PONCE (orgs). Psicologia \& Educação: perspectivas críticas para a ação psicopedagógica. Birigui: Boreal, 2012. p. 92-107.

CONSELHO FEDERAL DE PSICOLOGIA. Referências técnicas para atuação de psicólogas (os) na educação básica. Brasília: Conselho Federal de Psicologia, 2013.

COLLARES, C. L.; MOYSÉS, M. A. A. A transformação do espaço pedagógico em espaço clínico: a patologização da Educação. São Paulo: FDE, 1994. p.25-31.

DAVIDOV, V. La enseñanza escolar y El desarrollo psiquico. Tradução de Marta Shuare. Moscou: Progresso, 1988.

FRANCO, A. F. Reflexões em torno do encaminhamento da queixa escolar e a produção do fracasso escolar franco In: CONGRESSO NACIONAL DE EDUCAÇÃO, 9., 2009. Anais... [S.I.]: EDUCERE; PUC-PR, 2009.p. 5181-5187,2009.
LEONARDO, N.S.T.;LEAL, Z.F.R.G.;FRANCO, A.F. (Orgs.). $O$ processo de escolarização e a produção da queixa escolar: reflexões a partir de uma perspectiva crítica em psicologia. Maringá: Eduem, 2014.

MACHADO, A. M.; SOUZA, M. P. R. (Orgs.). Psicologia escolar: em busca de novos rumos. 3.ed.São Paulo: Casa do Psicólogo, 2001.

MACHADO, A. M. Relato de uma intervenção na escola pública. In: MACHADO, A. M.; SOUZA, M. P. R. (Orgs.). Psicologia escolar: em busca de novos rumos. São Paulo: Casa do Psicólogo, 1997. p. $87-100$.

MARTINS, L.M.; MARSIGLIA, A.C.G. As perspectivas construtivistas e histórico-crítica sobre o desenvolvimento da escrita. Campinas: Autores Associados, 2015.

MEIRA, M.E. M. Psicologia escolar: pensamento crítico e práticas profissionais. In: MACHADO, A. M.; SOUZA, M. P. R. (Orgs.). Psicologia escolar: em busca de novos rumos. 3. ed. São Paulo: Casa do Psicólogo, 2001.

MEIRA, M.E.M.; FACCI, M. G. D. (Orgs.). Psicologia histórico-cultural : contribuições para o encontro entre a subjetividade e a educação. São Paulo: Casa do Psicólogo, 2007.

MEIRA, M.E.M. Prefácio. In: LEONARDO, N.S.T.; LEAL, Z.F.R.G.; FRANCO, A.F. (Orgs.). O processo de escolarização e a produção da queixa escolar: reflexões a partir de uma perspectiva crítica em psicologia. Maringá: Eduem, 2014.

NUNES, R.L.; VIOTTO FILHO, I.A.T. A atividade do jogo e suas implicações para o desenvolvimento da consciência da criança na escola. Curitiba: CRV, 2016.

OLIVEIRA, B. O trabalho educativo. Campinas: Autores Associados, 1996.

PATTO, M. H. S. A produção do fracasso escolar: histórias de submissão e rebeldia. São Paulo: Casa do Psicólogo, 1996.

PATTO, M. H. S. Mutações do cativeiro: escritos de psicologia e política. São Paulo: Hacker Ed.; Edusp, 2000. 
RIBEIRO, M.L.S. Educação escolar: que prática é essa?. Campinas: Autores Associados, 2001.

SANNINO, A. Activity theory as an activist and interventionist theory. Theory\&Psychology, v. 21, p. 571-597, 2011. https://doi.org/10.1177/0959354311417485

SAVIANI, D. Educação: do senso comum à consciência filosófica. São Paulo: Cortez; Autores Associados, 2000.

SAVIANI, D. Pedagogia histórico-crítica: primeiras aproximações. Campinas: Autores Associados, 2001.

SAWAIA, B. As artimanhas da exclusão. São Paulo: Vozes, 2000.

SOUZA, M. P. R. Psicologia Escolar e políticas públicas em educação: desafios contemporâneos. Em Aberto, Brasília, v. 23, n. 83, p. 129-149, 2010.

TANAMACHI, E.; PROENÇA, M.;ROCHA,M. (Orgs.).Psicologia e educação: desafios teóricopráticos. São Paulo: Casa do Psicólogo, 2000.

THIOLLENT, M. Metodologia da pesquisa-ação. São Paulo: Cortez, 2000.

VAZQUEZ, A.S. Filosofia da práxis. Rio de Janeiro: Paz e Terra, 1988.

VIOTTO FILHO, I. A. Psicologia escolar e psicologia social-comunitária: diálogos para a construção de uma perspectiva crítica de atuação do psicólogo na escola. 2005. Tese (Doutorado em Educação/Psicologia da Educação) Programa de Psicologia da Educação, PUC/SP, São Paulo, 2005.

Recebido para publicação em: 02/10/2017

Revisado em: 06/11/2017

Aceito em: 22/01/2018 